\title{
Effect of Hypersensitivity on Protein Uptake Across the Air-Blood Barrier of Isolated Rabbit Lungs
}

\author{
Janet F. Braley, Laurence B. Peterson, Christopher A. Dawson, and \\ VERNON L. MOORE, Research Service, Veterans Administration Medical Center, \\ Wood (Milwaukee), Wisconsin 53193; Departments of Medicine and Physiology, \\ Medical College of Wisconsin, Milwaukee, Wisconsin 53226; Department of \\ Biology, Marquette University, Milwaukee, Wisconsin 53233
}

A B S T RACT In previous studies with isolated perfused rabbit lungs, we observed that human serum albumin (HSA) and ovalbumin, introduced into the isolated lungs as an aerosol, entered the pulmonary circulation antigenically intact. The "inhaled" proteins were also broken down in the lung. When lungs from animals immunized with one protein inhaled the two proteins simultaneously, absorption of intact antigen was specifically reduced, and there was a nonspecific increase in the appearance of metabolites of both proteins in the blood.

In the present study, we investigated the antigenspecific and nonspecific effects of two types of hypersensitivity responses on protein absorption across the air-blood barrier of isolated rabbit lungs. In one group of lungs, an acute hypersensitivity response was induced by introducing HSA into the blood perfusing lungs from HSA-immunized rabbits. In another, the rabbits had been previously exposed to chronic HSA aerosol until their lungs exhibited a chronic immunologic inflammatory response. Lungs from both groups were insufflated simultaneously with HSA, and a nonspecific protein, ovalbumin. Lungs in which the acute anaphylactic response was induced showed no alteration in the absorption of either intact protein compared with HSA-immunized controls, but absorbed a somewhat larger quantity of breakdown products of the specific antigen. Lungs undergoing the chronic

Dr. Braley was the recipient of a National Research Service Institutional Award, AI 07006. Her present address is Department of Microbiology, University of Tennessee Medical School, Memphis, Tenn. 38163. Dr. Peterson's present address is Yalem Research Laboratory, Jewish Hospital of St. Louis, St. Louis, Mo. 63178.

Address reprint requests to Christopher A. Dawson, Ph.D., Research Service/151, Veterans Administration Medical Center, Wood, Wis. 53193.

Received for publication 24 July 1978 and in revised form 22 January 1979. alveolar inflammation were more permeable to nonspecific protein than were noninflamed lungs. Despite the increased permeability to nonspecific protein, the absorption of antigen was blocked as effectively as in immune but noninflamed controls. In these chronically inflamed lungs, the absorption of antigen breakdown products was enhanced. The results indicate that both immunologic and inflammatory mechanisms may control the amounts of inhaled soluble proteins that reach the blood via the alveolocapillary barrier. Alterations in the absorption of inhaled proteins and their metabolites across the air-blood barrier during certain types of hypersensitivity responses may be of immunologic and pathologic significance.

\section{INTRODUCTION}

Inhaled antigens are implicated in a number of immunologic diseases of the lung. However, little is known about the fate of antigens, especially soluble proteins, in the lower respiratory tract or how their fate may be modified by immunologic and inflammatory processes.

In previous studies (1-3), we used isolated perfused rabbit lungs to investigate the effect of immunization on absorption of inhaled albumins across the alveolocapillary membrane into the blood. We found that humoral immunity resulted in an immunologically specific decrease in the absorption of intact antigens from the alveoli and a nonspecific increase in absorption of antigen breakdown products. This may partially explain observations in vivo that less intratracheally instilled antigen could be recovered from the blood of immunized than nonimmunized rabbits (4).

Under certain circumstances, the immune response can result in harmful reactions termed "hypersensitivity." It is not known whether these inflammatory reactions may also alter protein absorption from the airways. The purpose of the present study was to investigate 
the uptake of specific antigen and an immunologically unrelated protein across the alveolocapillary membrane of isolated rabbit lungs undergoing two different types of hypersensitivity reactions. To assess the effect of an acute hypersensitivity response on protein absorption, we used an in vitro model of rabbit anaphylaxis developed in our laboratory (5). To assess the effect of chronic hypersensitivity on protein absorption, we used a rabbit model of hypersensitivity pneumonitis, also developed in our laboratory (6). The results indicate that, whereas the acute hypersensitivity reaction did not alter the absorption of intact inhaled proteins, chronic hypersensitivity increased permeability of the air-blood barrier to an immunologically unrelated protein. However, in spite of this increased permeability, the absorption of specific antigen was blocked as effectively as in lungs from immunized rabbits that were not inflamed.

\section{METHODS}

Antigens. Human serum albumin (HSA) and ovalbumin (OA) were obtained from Miles Laboratories, Inc. (Elkhart, Ind.), complete Freund's adjuvant from Difco Laboratories (Detroit, Mich.), and HSA labeled with ${ }^{131}$ I from Mallinckrodt Inc. (St. Louis, Mo.). Sodium iodide (125I) was obtained from Amersham Corp. (Arlington Heights, Ill.) and was used to label OA by the iodine monochloride method of Bale et al. (7). The free ${ }^{131} \mathrm{I}$ and ${ }^{125} \mathrm{I}$ were removed by dialysis against excess $0.15 \mathrm{M} \mathrm{NaCl}$ at $4^{\circ} \mathrm{C}$.

Treatment of animal groups. New Zealand white rabbits of either sex were immunized subcutaneously in two inguinal sites with $2 \mathrm{mg}$ of HSA in complete Freund's adjuvant, and 2 wk later they were given a second $2 \mathrm{mg}$ of HSA in complete Freund's adjuvant subcutaneously. $2 \mathrm{wk}$ after the second injection, 10 rabbits were used for studies of anaphylaxis and 14 were exposed to aerosolized HSA daily for $3 \mathrm{wk}$ before use in studies of lungs undergoing a chronic hypersensitivity reaction. Before isolation of the lungs, the antibody titer was measured on serum from each rabbit in both groups by using a tanned sheep erythrocyte passive hemagglutination assay (8). The geometric mean HSA antibody titer in the serum of all HSA-immunized animals was 1:3,200 at the time of the experiment. There was no significant alteration in circulating antibody titer after 3 wk of HSA aerosol exposure. The rabbits weighed $3.2-3.7 \mathrm{~kg}$ at the time the lungs were studied.

Isolated perfused lung preparations. Isolated rabbit lungs were mounted in a chamber where they were ventilated with negative pressure and perfused at a constant rate $(160 \mathrm{ml} / \mathrm{min})$ with autochthonous blood for $4 \mathrm{~h}$, as described (1). Inhaled proteins were introduced into the lung as an aerosol; $100 \mu \mathrm{Ci}$ of freshly dialyzed ${ }^{131} \mathrm{I}-\mathrm{HSA}$ (antigen) and $20 \mu \mathrm{Ci}$ of ${ }^{125} \mathrm{I}-\mathrm{OA}$ (nonimmunizing protein), diluted in $5 \mathrm{ml}$ of $0.15 \mathrm{M}$ saline, were aerosolized simultaneously with an ultrasonic nebulizer. The lungs were insufflated with the aerosol for $15 \mathrm{~min}$. The nebulizer was then removed, and the lungs were ventilated and perfused for $4 \mathrm{~h}$, during which time blood samples were taken. Approximately $1 / 3 \mathrm{ml}$ of inspired vapor, containing $0.2-1.0 \mathrm{mg}$ HSA and $0.7 \mathrm{mg} \mathrm{OA}$, was retained by the lungs. Pulmonary arterial blood pressure and the volume of blood in the reservoir included in the closed perfusion circuit were monitored throughout the experiments.

${ }^{1}$ Abbreviations used in this paper: HSA, human serum albumin; OA, ovalbumin.
Collection of samples and calculations. 1-ml blood samples were taken every $30 \mathrm{~min}$ for $4 \mathrm{~h}$ after the beginning of antigen inhalation. Total counts per minute (cpm), which had entered the blood by the end of each time interval, were calculated from the activity of the sample, and the circulating blood volume corrected for volume lost in sampling. At the end of each experiment, the lungs were weighed and cut into slices for measurement of radioactivity. The inhaled dose of radioactivity was determined by adding the counts per minute found in the blood and lung at the end of the experiment.

The blood samples were analyzed as described (1). Each sample was centrifuged at $2,000 \mathrm{~g}$ for $15 \mathrm{~min}$. Less than $1 \%$ of the whole blood counts per minute remained with the cells washed three times with 5 vol physiologic saline. An aliquot of plasma was precipitated with 5\% TCA to determine the fractions of TCA-soluble and TCA-precipitable radioactivity, and the TCA fractions of plasma from each group of animals were further characterized, as described (1); antigenically intact radioactivity in the plasma was assessed by coprecipitation with pooled rabbit antiserum and antigen at equivalence. The small molecular weight TCA fractions were separated on thinlayer chromatography. Radioactivity was measured in a Packard model 575 gamma radiation counter (Packard Instrument Co., Inc., Downers Grove, Ill.).

Data are reported as percent of inhaled counts per minute entering the plasma in the TCA-precipitable and TCA-soluble fractions as a function of time, and the mean value of experimental groups at each sample time were compared by using Student's unpaired $t$ test.

Influence of anaphylaxis on absorption through isolated perfused lungs. In experiments on absorption of inhaled proteins during anaphylaxis, specific antigen, ${ }^{131}$ I-HSA, and an immunologically nonspecific protein, ${ }^{125}$ I-OA, were aerosolized for $15 \mathrm{~min}$ into the isolated perfused lungs of six of the HSA-immune rabbits. Then, $1 \mathrm{mg}$ of unlabeled HSA was added to the blood perfusing the lung to induce an anaphylactic response, as described (5). To determine the fate of proteins injected directly into the blood, $1 \mathrm{mg}$ each of ${ }^{131} \mathrm{I}-\mathrm{HSA}$ and ${ }^{125}$ I-OA was added to blood perfusing lungs from four of the HSA-immune rabbits. In two of the four experiments, the proteins were infused directly into the pulmonary artery. In the other two experiments, the proteins were allowed to equilibrate with the blood for $3 \mathrm{~min}$ before entering the pulmonary artery.

Influence of chronic hypersensitivity on absorption through isolated perfused lungs. The rabbits immunized with subcutaneous injections of HSA followed by daily exposure to HSA aerosol were used in these experiments. This procedure results in the development of immunologically specific chronic granulomatous inflammation as well as cell-mediated hypersensitivity in the lungs, as assessed by migration inhibitory testing (6). The lungs were studied $16 \mathrm{~h}$ after the last in vivo aerosol exposure. Five animals were used to confirm the presence of pulmonary inflammation and cell-mediated hypersensitivity, and the lungs of nine animals were studied in the isolated perfusion system for absorption of inhaled proteins. Lung sections for histologic examination were fixed in Zenker's solution and prepared for routine hemotoxylin and eosin staining. The presence of pulmonary cell-mediated hypersensitivity was tested in a direct macrophage migration inhibitory assay with bronchoalveolar cells lavaged from the lungs as described (9).

Controls. Two groups of controls were studied. Lungs from 11 nonimmunized rabbits were used to demonstrate the "normal" absorption of proteins and their metabolites from isolated lungs. Lungs from $10 \mathrm{HSA}$-immunized rabbits that had not received the chronic aerosol treatment were studied without the anaphylactic challenge. These lungs served to 
illustrate the alterations in protein absorption that were the result of immunization per se. Thus, any further alterations in protein absorption were the result of the hypersensitivity response.

\section{RESULTS}

Radioactivity in blood of isolated lungs. As in our previous studies with isolated rabbit lungs (1), radioactivity from inhaled ${ }^{131}$ I-HSA and ${ }^{125}$ I-OA entered the pulmonary circulation of all the lungs studied in two fractions. One fraction was precipitable with $5 \%$ TCA and was also precipitable with antiserum (anti-HSAprecipitable ${ }^{131} \mathrm{I}=0.959 \times$ TCA-precipitable ${ }^{131} \mathrm{I}$; antiOA-precipitable ${ }^{125} \mathrm{I}=0.981 \times$ TCA-precipitable ${ }^{125} \mathrm{I}$ ) and is therefore considered to be antigenically intact protein. The other fraction was TCA soluble. Thinlayer chromatography in this TCA-soluble fraction, carried out as described (1), showed radioactivity in several bands. Approximately $80 \%$ of the ${ }^{131}$ I on the TLC plates had mobility different from that of ${ }^{125} \mathrm{I}$ labeled sodium iodide which was used as a standard, indicating that most of the TCA-soluble ${ }^{131} \mathrm{I}$ was not free iodine and that this fraction probably represents primarily iodinated amino acids and peptides.

Protein absorption from isolated lungs after anaphylaxis. In vitro anaphylaxis was produced in isolated lungs from immunized animals by adding antigen to the perfusion system. Pulmonary arterial blood pressure rose in all lung preparations with a mean increase of $13.5 \mathrm{~mm} \mathrm{Hg} \pm 3.7 \mathrm{SE}$. The peak pressure was reached at $\cong 6 \mathrm{~min}$ and returned to base line within $15-30 \mathrm{~min}$. During the pressure changes, there were also alterations in fluid volume of the lungs, as indicated by immediate volume changes in the perfusion reservoir. These volume changes were variable, consisting of a shift of 0.5-2.5 ml either out of the lung, into the lung, or both, in a biphasic fashion. The fluid volume returned to prechallenge levels following approximately the same time-course as the blood pressure changes. The initial arterial blood pressure of these lungs was $7.8 \mathrm{~mm}$ $\mathrm{Hg} \pm 0.8 \mathrm{SE}$, which was not significantly different from normal or immunized controls $(7.0 \mathrm{~mm} \mathrm{Hg} \pm 0.4 \mathrm{SE}$ ). However, by the end of the 4-h experiment the mean arterial pressure had risen slowly to an average of 26.4 $\mathrm{mm} \mathrm{Hg} \pm 6.6 \mathrm{SE}$, which was approximately twice as high as control values $(12.4 \mathrm{~mm} \mathrm{Hg} \pm 0.6 \mathrm{SE}, P<0.001)$ at the end of the experiments. The mean lung weight to body weight ratio at the end of the experiment (3.7 $\mathrm{g} / \mathrm{kg}$ ) was not significantly different from control (3.5 $\mathrm{g} / \mathrm{kg}$ ), indicating that edema formation was not excessive. The absorption of inhaled proteins by these lungs is summarized in Figs. 1 and 2.

The data in Fig. 1 show the percent of radioactivity from specific inhaled antigen, ${ }^{131}$ I-HSA, which appeared in the plasma in the TCA-precipitable and the TCA-soluble fractions collected from the HSA-immune

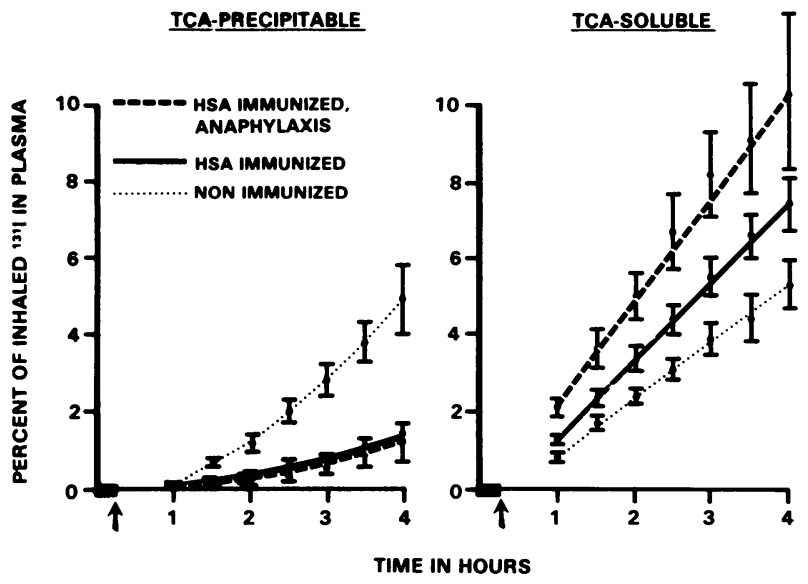

FIGURE 1 Time-course of the appearance of TCA-precipitable and TCA-soluble ${ }^{131} I$ in the plasma of isolated perfused lungs insufflated with ${ }^{131} \mathrm{I}-\mathrm{HSA}$ and ${ }^{125} \mathrm{I}-\mathrm{OA}$. The dark bar represents $15 \mathrm{~min}$ of insufflation. Each point represents the mean $\pm S E$ of the percent of inhaled ${ }^{131} I$ in the plasma. Lungs from HSA-immunized rabbits were given an anaphylactic challenge with $1 \mathrm{mg}$ unlabeled HSA i.v. (at arrow). The controls (antigen not added to blood) consist of lungs from HSAimmunized rabbits and lungs from nonimmunized rabbits.

lungs undergoing anaphylaxis. The results are compared with those from the HSA-immune lungs, which were not subjected to anaphylaxis, and to lungs from normal non-HSA-immune rabbits. The amount of TCAprecipitable ${ }^{131} I$ in the plasma of lungs that had undergone anaphylaxis was significantly reduced relative to lungs from normal non-HSA-immune rabbits, amounting to a fourfold reduction at $4 \mathrm{~h}$. The difference was significant at all points with $P<0.005$ by the first $1.5 \mathrm{~h}$. This reduction was comparable to that in immune lungs not subjected to anaphylactic challenge. The TCA-

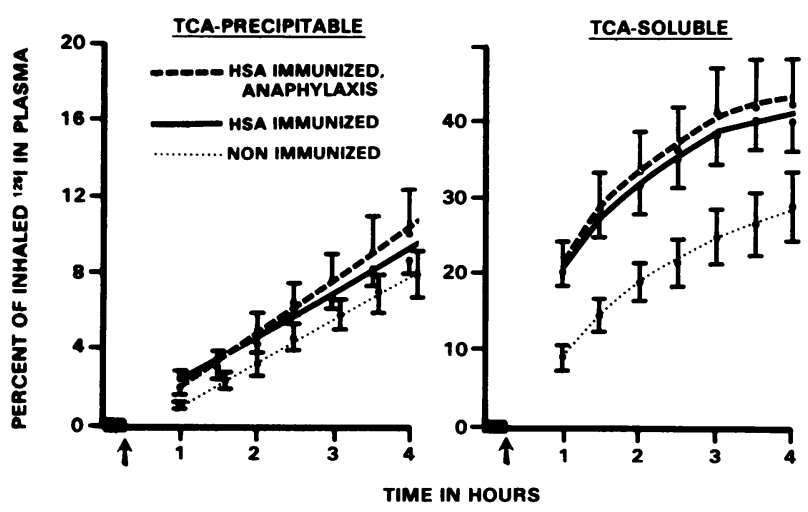

FIGURE 2 The percent $\pm S E$ of inhaled dose of ${ }^{125}$ I appearing in the plasma of isolated lungs (same lungs as in Fig. 1) in the TCA-precipitable and TCA-soluble fractions after 15 min (dark bar) of insufflation with ${ }^{131}$ I-HSA and ${ }^{125}$ I-OA. Anaphylaxis was elicited (at arrow) in immunized preparations but not in HSAimmunized and nonimmunized controls. 
soluble ${ }^{131} \mathrm{I}$ in the plasma of lungs undergoing anaphylaxis was almost twice as high as that seen in the plasma of normal lungs $(P<0.001$ by $1 \mathrm{~h}$ ) and was $\cong 40 \%$ higher than in the immune controls, although this difference was statistically significant through only the $3 \mathrm{rdh}$ $(P<0.05)$.

Fig. 2 shows absorption of a nonimmunologically specific protein, ${ }^{125} \mathrm{I}-\mathrm{OA}$, from the same lungs. The TCA-precipitable fraction was absorbed similarly in all three groups. The amount of TCA-soluble ${ }^{125 I}$ in the plasma of immune lungs undergoing anaphylaxis was more than twice as high as that of nonimmune lungs by $1 \mathrm{~h}(P<0.01)$ but was similar to that of the immunized controls which did not undergo anaphylaxis.

Fate of proteins injected directly into the blood of isolated lungs. To determine the fate of the antigen injected intravascularly to produce anaphylaxis, ${ }^{131} \mathrm{I}$ HSA and ${ }^{125}$ I-OA were added directly to the perfusing blood of HSA-immune lungs. Fig. 3 is an example of the results. The concentration of ${ }^{131} \mathrm{I}-\mathrm{HSA}$ in the blood dropped precipitously. By the end of $3 \mathrm{~h}$, most of the ${ }^{131}$ I added had been cleared from the blood and was accounted for by radioactivity in lung tissue. Comparison of the specific activity (counts per minute per milliliter) of fresh plasma in the first blood sample $(5 \mathrm{~min})$ with specific activity of whole blood revealed that most of the blood ${ }^{131}$ I ( $\left.\cong 93 \%\right)$ was with the cell pellet after centrifugation, indicating that antigen at this time was either insoluble or associated with cells. In contrast, ${ }^{125}$ I-OA remained soluble in the plasma and was not taken up by the lung. The specificity of this response for the immunizing protein was shown in other experiments with OA-immunized lung preparations; in

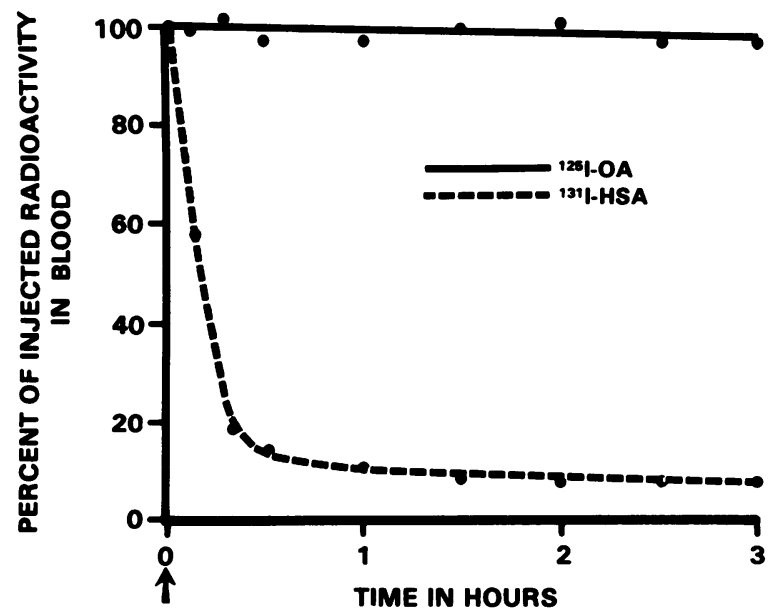

FIGURE 3 The fate of specific antigen ( ${ }^{131}$ I-HSA) and a nonspecific protein ( $\left.{ }^{125} \mathrm{I}-\mathrm{OA}\right)$ in the blood of the isolated lung from an HSA-immunized rabbit. $1 \mathrm{mg}$ of each protein was injected into the blood (at arrow), producing a rise in blood pressure that reached its peak after $6 \mathrm{~min}$. this case, only OA was initially found in the cell pellet and accumulated in the lung.

An increase in pulmonary arterial pressure was produced in all experiments in which antigen was added directly to the pulmonary arterial blood of immune lung preparations. However, in the two experiments in which the proteins equilibrated with blood for $3 \mathrm{~min}$ before they were allowed to enter the lung, no anaphylactic response occurred despite the fact that the antigen was taken up by the lung in the same time-course as when antigen was added directly into the pulmonary artery, suggesting that the increase in pulmonary arterial pressure during anaphylaxis was not solely due to the mechanical effects of complexes and that vasoactive mediators were also involved.

Protein absorption from isolated lungs with a chronic hypersensitivity inflammatory response. We produced a chronic pulmonary inflammatory response to HSA as described by Peterson et al. (6). Rabbits immunized to HSA by subcutaneous injection were given daily aerosol exposures to antigen for $3 \mathrm{wk}$, after which their lungs were heavier than controls, with a lung weight to body weight ratio of $5.6 \pm 1 \mathrm{~g} / \mathrm{kg}$ compared with a ratio of $3.5 \pm 0.1 \mathrm{~g} / \mathrm{kg}$ for lungs of normal rabbits and rabbits immunized but not chronically exposed to the aerosol. Histologic examination (Fig. 4) showed diffuse interstitial thickening as a result of a dense infiltration of mononuclear cells. The response also included occasional granulomas and increased numbers of granulocytes. In the presence of specific antigens, bronchoalveolar cells from all five inflamed lungs tested were inhibited $>30 \%(P<0.05)$ in the presence of HSA in the direct migration inhibitory assay. The lungs from normal rabbits and from immunized rabbits not chronically exposed to aerosol were normal histologically, and migration of bronchoalveolar cells from these animals was not inhibited in the presence of HSA. During the $4 \mathrm{~h}$ of study in the isolated perfusion system, pulmonary arterial blood pressure of aerosol-inflamed lungs rose from $8.3 \mathrm{~mm} \mathrm{Hg} \pm 1.54 \mathrm{SE}$ (not significantly different from controls, $7.0 \mathrm{~mm} \mathrm{Hg}$ $\pm 0.4 \mathrm{SE}$ ) to $21.2 \mathrm{~mm} \mathrm{Hg} \pm 3.6 \mathrm{SE}$, which was $\cong 50 \%$ higher than in noninflamed lungs $(12.4 \mathrm{~mm} \mathrm{Hg} \pm 0.6$ SE, $P<0.005$ ).

In Figs. 5 and 6, absorption of ${ }^{131}$ I-HSA and ${ }^{125}$ I-OA from inflamed lungs of nine HSA-immunized, aerosolexposed rabbits is compared with that of the two control groups. The uptake of TCA-precipitable antigen from the chronically inflamed lungs (Fig. 5) was reduced relative to nonimmune lungs $(P<0.005$ after $1.5 \mathrm{~h})$ but was not statistically different from lungs from immunized rabbits not chronically aerosol-exposed. On the other hand, greater amounts of the TCA-soluble products of antigen were absorbed from inflamed lungs than from either of the control groups; by the first $1.5 \mathrm{~h}$ 


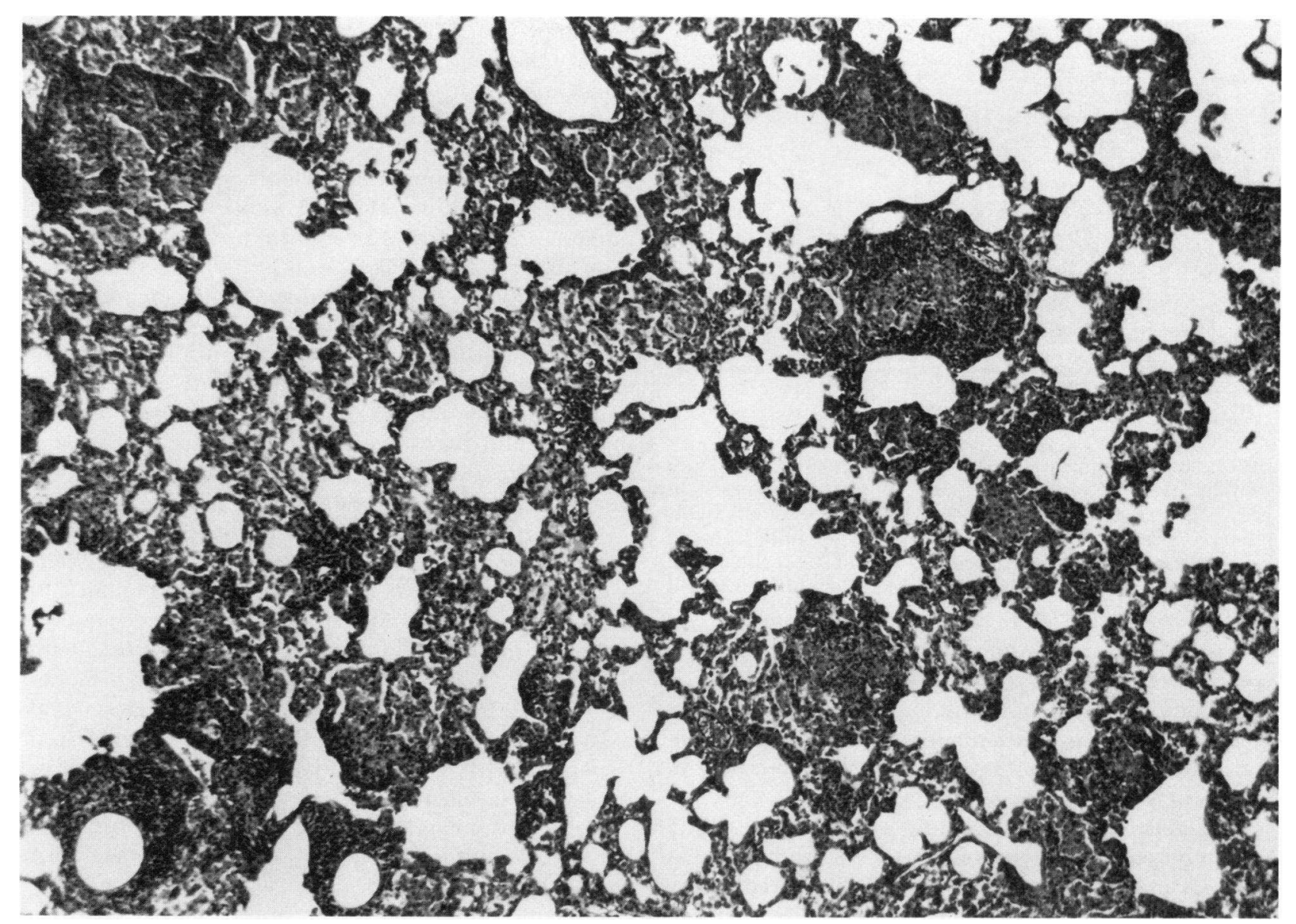

FIGURE 4 Lung tissue from a rabbit immunized subcutaneously with HSA in complete Freund's adjuvant and exposed to an aerosol of HSA daily for $3 \mathrm{wk}$. The alveolar membranes are infiltrated with mononuclear cells and granulomas are present. Hematoxylin and eosin, $\times 50$.

TCA-soluble ${ }^{131} \mathrm{I}$ was more than six times higher in the plasma of inflamed lungs than of nonimmune lungs $(P<0.001)$ and four and one-half times higher than in the immunized but noninflamed controls $(P<0.005)$.

It can be seen in Fig. 6 that about twice as much TCA-precipitable ${ }^{125} \mathrm{I}-\mathrm{OA}$ entered the plasma of inflamed than of noninflamed lungs $(P<0.02$ at $4 \mathrm{~h})$. The absorption of TCA-soluble ${ }^{125} \mathrm{I}$ from inflamed lungs appeared to be enhanced relative to nonimmune lungs, but the difference was only statistically significant from 1.5 through $3 \mathrm{~h}(P<0.05)$ and no different from immune controls.

\section{DISCUSSION}

The results of this study indicate that the absorption of inhaled radioiodinated proteins across the alveolocapillary membrane of isolated lungs is altered during certain types of hypersensitivity reactions. Isolated lungs from HSA-immunized rabbits were insufflated

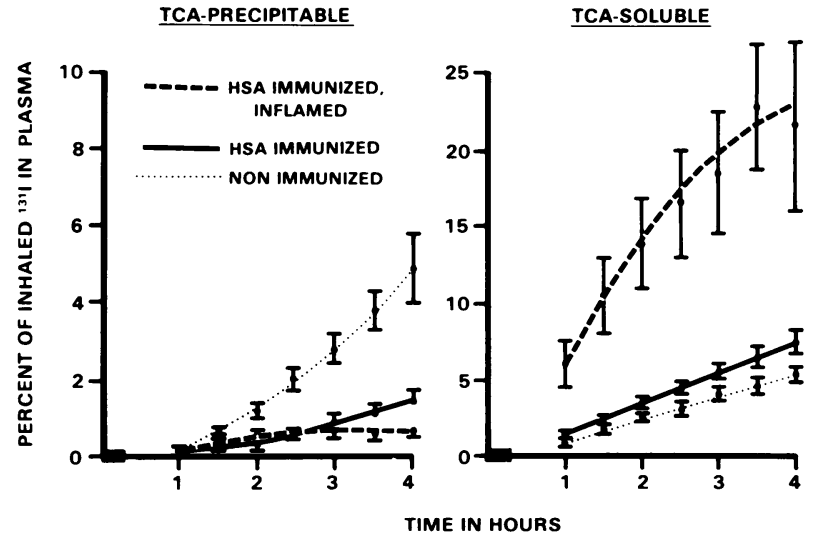

Figure 5 The appearance of TCA-precipitable and TCAsoluble ${ }^{131} \mathrm{I}$ in the plasma of isolated lungs after $15 \mathrm{~min}$ (dark bar) of insufflation with ${ }^{131}$ I-HSA and ${ }^{125}$ I-OA. Each point represents the mean $\pm S E$ of the percent of inhaled ${ }^{131} I$ in the plasma of HSA-immunized and aerosol-exposed lungs compared with HSA-immunized and nonimmunized controls. 


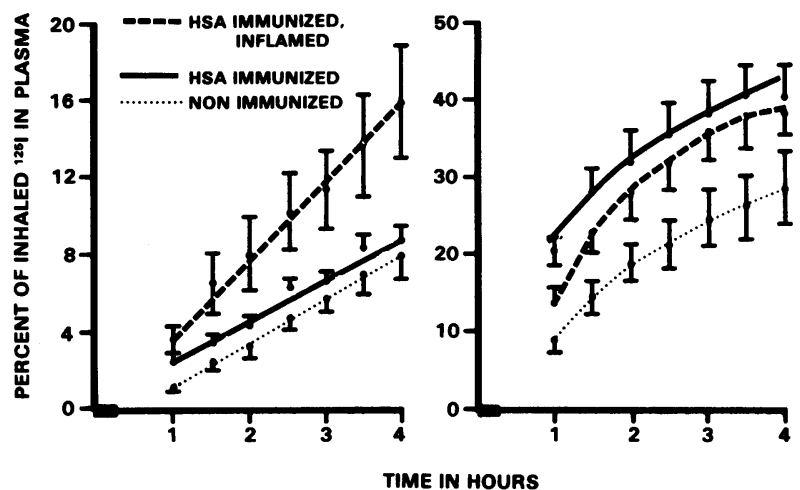

FIGURE 6 The appearance of TCA-precipitable and TCAsoluble ${ }^{125} \mathrm{I}$ in the plasma of isolated lungs (same lungs as in Fig. 5) after insufflation (dark bar) with ${ }^{131}$ I-HSA and ${ }^{125}$ I-OA. Each point represents the mean $\pm S E$ of the percent of inhaled ${ }^{125} \mathrm{I}$ in the plasma of HSA-immunized and aerosol-exposed lungs compared with HSA-immunized and nonimmunized controls.

with ${ }^{131}$ I-HSA to assess the specific effects of hypersensitivity on antigen absorption. An unrelated protein (125I-OA) was inhaled simultaneously to assess the nonspecific effects of the immune reaction on protein absorption.

To determine whether protein uptake is altered by an acute hypersensitivity response, we produced anaphylaxis in isolated lungs from immunized rabbits by adding antigen to the pulmonary blood. The response elicited has been demonstrated by Hakim et al. (5) to be similar to that described in intact rabbits, namely, a marked increase in pulmonary vascular resistance, increased airway resistance, and decreased lung compliance. The absorption of intact proteins (antigen and nonantigen) from immune lungs undergoing anaphylaxis was no different than from immune control lungs, i.e., HSA absorption was specifically reduced in HSAimmune lung preparations, whereas $\mathrm{OA}$ was absorbed to the same extent as in nonimmune preparations. This suggests that the rate-limiting transport mechanism for protein across the alveolocapillary membrane was not changed by the anaphylaxis under the conditions of these studies.

Boucher et al. reported that induction of anaphylaxis in guinea pigs by local application of antigen (10) or infusion of histamine or methacholine (11) resulted in an increased permeability of the respiratory mucosa to nonspecific protein. They also found an increase in absorption of albumin or albumin breakdown products through the airways of Ascaris suum-sensitive rhesus monkeys after antigen challenge (12).

It is difficult to compare results from other species using different preparations. For example, even though the rabbit and guinea pig share a common shock organ, namely the lung, the responses in the two species are substantially different. Rabbit anaphylaxis occurs in response to blood-borne antigen and is not easily elicited by antigen introduced into the airways. Bloodborne mediators, including vasoactive amines from circulating blood cells $(13,14)$ as well as circulating immune complexes (15), appear to be primarily responsible for the changes seen in lung physiology.

In addition to species differences in the anaphylactic response, the routes available for absorption differ in different preparations. In the isolated lung, the alveolocapillary membrane is the only route available for entry of antigen into the blood. Thus, it would appear that in rabbit lungs the acute anaphylactic response did not have a significant influence on protein absorption through the alveolocapillary membrane.

To study the effects of chronic hypersensitivity on protein absorption, we used a rabbit model of hypersensitivity pneumonitis recently developed in our laboratory (6). In immunized rabbits, prolonged aerosol exposure to antigen produced diffuse alveolitis with thickening of the air-blood barrier, extensive mononuclear cell infiltration with granuloma formation, and a moderate granulocyte infiltration. Cell-mediated hypersensitivity could be demonstrated in these lungs with a direct macrophage migration inhibitory assay. This type of inflammation did not alter absorption of the specific antigen from isolated lungs as intact HSA was absorbed to the same extent as from HSA-immune, noninflamed lungs. However, approximately twice as much simultaneously inhaled OA entered the plasma of inflamed lungs as that of controls, apparently because of a nonspecific increase in protein permeability in the inflamed lungs. The type(s) of immune reaction responsible for increased protein permeability cannot be determined from the present experiments. A local humoral mechanism may have been involved, because chronic pulmonary antigen exposure can stimulate local antibody synthesis (16). Alternatively, there is evidence that chronic antigen stimulation in the presence of cell-mediated hypersensitivity can cause structural damage to lung tissues (17), conceivably resulting in a "leaky" air-blood barrier.

Absorption of the specific antigen from these chronically inflamed lungs appeared to be effectively blocked, even in the presence of increased permeability to the nonspecific protein. In addition, there was a threefold increase in the amount of metabolic products of HSA in the plasma, a specific effect on antigen not seen for OA. This suggests two possible explanations for the data concerning specific antigen absorption: (a) Either antigen was blocked before entering the blood, perhaps because of the formation of immune complexes in the lung, and was subsequently catabolized to a greater 
extent as a result of the increased number (or state of activation or antigen specificity) of phagocytic cells in the inflamed lungs; or $(b)$ intact antigens may have entered the alveolar capillaries at a greater rate than normal (as a result of increased protein permeability) but formed immune complexes in the blood that were then rapidly removed from the circulation by reuptake into the lung. The question of whether other organs of the body may be exposed to greater loads of antigen or complexes in this pulmonary inflammatory disorder is of great immunologic and pathologic importance. This rabbit model has many similarities to human hypersensitivity pneumonitis in which lung biopsies frequently exhibit chronic granulomatous inflammation which is probably associated with pulmonary cellmediated hypersensitivity $(18,19)$. In addition, these patients have large quantities of circulating antibodies to inhaled antigen (20). Extension of the present study should provide a greater understanding of the fate of inhaled antigen and how normal handling of environmental antigen is modified by inflammation and im: munologic reactions.

\section{ACKNOWLEDGMENTS}

We greatly appreciate the excellent assistance of Mrs. Victoria M. Wagner-Weber and wish to thank Mrs. Pamela J. Staab and Catherine A. Walther for typing and editing the manuscript. We also appreciate the suggestions of Dr. Jordan N. Fink, Medical College of Wisconsin.

The work was supported by grant HL 19733 from the National Heart, Lung, and Blood Institute and the Medical Research Service of the Veterans Administration, and was aided by Specialized Center of Research grant HL 15389 from the National Institutes of Health.

\section{REFERENCES}

1. Braley, J. F., C. A. Dawson, V. L. Moore, and B. O. Cozzini. 1978. Absorption of inhaled antigen into the circulation of isolated lungs from normal and immunized rabbits. J. Clin. Invest. 61: 1240-1246.

2. Braley, J. F., C. A. Dawson, and V. L. Moore. 1978. Immunologic block against antigen absorption from isolated perfused rabbit lungs. J. Immunol. 121: 926-929.

3. Dawson, C. A., J. F. Braley, and V. L. Moore. 1979. Influence of immunity on the absorption of inhaled antigen. Chest. 75(Suppl.): 276-278.

4. Thrall, R. S., L. B. Peterson, J. H. Linehan, P. Abramoff, and V. L. Moore. 1978. The effect of immunization on the uptake of intratracheally-administered antigen. Clin. Immunol. Immunopathol. 10: 136-147.
5. Hakim, T. S., C. A. Dawson, V. L. Moore, and J. J. Barboriak. 1978. Anaphylaxis in isolated rabbit lungs. Respiration. 36: 153-159.

6. Peterson, L. B., J. F. Braley, and V. L. Moore. 1979. Experimental hypersensitivity lung disease. Chest. 75 (Suppl.): 274-276.

7. Bale, W. F., R. W. Helmkamp, T. P. Davis, M. J. Izzo, R. L. Goodland, M. A. Contreras, and I. L. Spar. 1966. High specific activity labeling of protein with ${ }^{131} \mathrm{I}$ by the iodine monochloride method. Proc. Soc. Exp. Biol. Med. 122: 407-413.

8. Campbell, D. H., F. S. Garvey, N. E. Cremer, and D. H. Sussdorf. 1970. In Methods in Immunology. W. A. Benjamin, Inc., Menlo Park, Calif. 2nd edition. 246-250.

9. Moore, V. L., G. T. Hensley, and J. N. Fink. 1975. An animal model of hypersensitivity pneumonitis in the rabbit. J. Clin. Invest. 26: 937-944.

10. Boucher, R. C., V. Rauga, P. D. Pare, L. A. Moroz, and J. C. Hogg. 1977. The effect of allergic bronchoconstriction on respiratory mucosal permeability. Physiologist. 20: 11A. (Abstr.)

11. Boucher, R. C., V. Rauga, P. D. Pare, S. Inoue, L. A. Moroz, and J. C. Hogg. 1977. Effect of histamine and methacholine on respiratory mucosal permeability. Am. Rev. Respir. Dist. 115: 307A. (Abstr.)

12. Boucher, R. C., P. D. Pare, N. J. Gilmore, L. A. Moroz, and J. C. Hogg. 1976. Airway mucosal permeability in the Ascaris suum-sensitive rhesus monkey. J. Allergy Clin. Immunol. 60: 134-140.

13. Weigle, W. O., C. G. Cochrane, and F. J. Dixon. 1960. Anaphylactic properties of soluble antigen-antibody complexes in the guinea pig and rabbit. J. Immunol. 85: 469-477.

14. Henson, P. M., and C. G. Cochrane. 1971. Immune complex disease in rabbits. The role of complement and of a leukocyte-dependent release of vasoactive amines from platelets. J. Exp. Med. 133: 554-571.

15. McKinnon, G. E., E. C. Andrews, R. H. Heptinstall, and F. G. Germuth. 1957. An immunohistologic study on the occurrence of intravascular antigen-antibody precipitation and its role in anaphylaxis in the rabbit. Bull. Johns Hopkins Hosp. 101: 258-271.

16. Kaltreider, H. B. 1976. Expression of immune mechanisms in the lung. Am. Rev. Respir. Dis. 113: 347-379.

17. Gordon, S. 1977. Macrophage neutral proteinases and defense of the lung. Fed. Proc. 36: 2707-2711.

18. Hensley, G. T., J. C. Garancis, G. D. Cherayil, and J. N. Fink. 1969. Lung biopsies of pigeon breeder's disease. Arch. Pathol. 87: 572-579.

19. Reynolds, H. Y., J. D. Fulmer, J. A. Kazmierowski, W. C. Roberts, M. M. Frank, and R. C. Crystal. 1977. Analysis of cellular and protein content of bronchoalveolar lavage fluid from patients with idiopathic pulmonary fibrosis and chronic hypersensitivity pneumonitis. J. Clin. Invest. 59: 165-175.

20. Roberts, R. C., and V. L. Moore. 1977. Immunopathogenesis of hypersensitivity pneumonitis. Am. Rev. Respir. Dis. 116: 1075-1090. 